\title{
Réflexions sur l'acculturation
}

\author{
Colette Pétonnet et Éliane Daphy
}

[Référence de publications : Colette Pétonnet et Éliane Daphy, « Réflexions sur l'acculturation », Vibrations. Revue d'études des musiques populaires, $\mathrm{n}^{\circ} 1$ (Métissage et musique métissées, ss la dir. de Louis-Jean Calvet, 1985 (avril), pp. 28-38. ISBN 270896190 oai:halshs.ccsd.cnrs.fr:halshs-00004247_v1

http://halshs.ccsd.cnrs.fr/halshs-00004247]

Colette Pétonnet [C.P.] : Je suis un peu surprise, au premier abord, par le choix du terme métissage. C'est un terme d'anthropologie physique. Est métis l'enfant né de parents appartenant à des «races» différentes. S'il s'agit de la blanche et de la noire, il est dit mulâtre. Dans le cas d'un croisement entre «Blancs » et Asiatiques, les enfants sont Eurasiens. Notons la différence de vocabulaire. Je crains que le mot métissage ne soit entaché de quelque connotation infériorisante et que son choix ne soit pas innocent. De plus, alors que dans le métissage le double héritage génétique est fixé pour l'enfant-héritier, les héritages culturels sont multiples et mouvants. Les cultures évoluent constamment, procédant par emprunts et inventions. C'est pourquoi les ethnologues emploient peu ce terme en parlant de culture. Cependant Roger Bastide l'a utilisé dans le contexte particulier des religions brésiliennes, et aussi, je crois, l'ethnomusicologue Gilbert Rouget.

Éliane Daphy [E.D.] : C'est peut-être qu'il sous-tend (probablement de façon inconsciente) le fantasme selon lequel il existerait des cultures «pures ». Les folkloristes, par exemple, ont pendant longtemps abordé la musique populaire en valorisant son authenticité, sa pureté. Il y aurait, ou plutôt il y aurait eu des « cultures pures », comme il y aurait eu des « races pures». Or, on sait que pour Gobineau, le métissage était l'explication de la dégénérescence ... et, par ailleurs, les travaux des biologistes comme jacquard ont montré que le concept de race ne reposait sur aucune réalité scientifique. L'emploi de ce terme à propos de musique populaire est peut-être une manière de valoriser «à l'envers » la musique, en suggérant justement que sa valeur intrinsèque réside dans sa capacité à mixer, à mélanger différents éléments empruntés ici et là. 
Cette acception valorisante provient probablement aussi du constat que les musiciens sont souvent d'origines culturelles différentes : si l'on considère les «vedettes» de la chanson en France, on trouve des gens comme Dalida, Aznavour, ou Yves Montand. La question se pose alors de comprendre pourquoi les Français consacrent vedettes des « étrangers »?

C. P. : La rencontre entre gens d'origines diverses est d'une certaine façon le propre des milieux «professions artistiques ». Il s'agit toujours de gens venus d'ailleurs, qui se retrouvent autour d'un art commun; on peut prendre l'exemple des peintres de Montparnasse, où des artistes de cultures et d'origines différentes se reconnaissaient comme « collègues » par le partage d'un art commun.

E. D. : Cela me fait penser aux paroles de la chanson interprétée par julien Clerc : «Quand on est musicien, on est Américain si le coeur vous en dit », ou par Rachid Bahri: «Musicien voyageur, j'ai voyagé dans tous les pays sans savoir où bâtir mon nid, ce que je sais, ce que je suis, c'est la mémoire du voyageur, je suis un oiseau migrateur ».

Dans ce milieu, l'idée que la musique détermine davantage l'appartenance que l'origine ou la nationalité est très présente. Les musiciens professionnels sont amenés à se déplacer pour travailler, ce sont donc des nomades dans une société d'origine paysanne, ancrée sur un territoire. Comme les gens du cirque, les musiciens font partie des gens du voyage, et l'absence de racines «terriennes » fait d'eux des étrangers, comme les marins.

Et plutôt que de considérer comme discours « romantique », sans réalité sociale, la représentation du musicien «éternel, voyageur», il paraît plus fructueux de s'interroger sur l'origine de ces représentations. Les conditions de travail fournissent un axe d'interprétation : pour reprendre l'exemple des peintres à Montparnasse, je me demande dans quelle mesure la rencontre d'artistes de cultures différentes n'est pas fondée à la fois sur le partage d'un mode de vie, luimême distinct de la norme sociale, et d'une pratique technique commune qui permet de transcender les différences culturelles et les problèmes de communication, en structurant la rencontre et le dialogue sur des bases communes.

Mais ces explications s'adressent au monde des musiciens, elles n'éclairent guère la précédente question de savoir pourquoi Dalida est une vedette « française »...

C. P. : Il faut resituer cette question dans l'ensemble d'un contexte culturel : en même temps que l'on sacre vedette Dalida ou Aznavour, on oublie que Mozart ou Beethoven n'étaient pas Français ; la musique est transportée par l'oreille et la façon de la recevoir est différente des autres faits culturels, surtout avec la puissance actuelle des médias. Les gens adoptent un air qui leur plaît, qu'on le veuille ou non. Cela crée une diversité salutaire, qu'on ne peut réduire à une moyenne. C'est le principe même de la diversité qui fonde les différentes cultures.

E. D. : Ce qui tempère un peu les affirmations manichéennes selon lesquelles les industries du «show-biz» auraient le moyen de manipuler entièrement les goûts musicaux, en imposant leurs produits, ce qui conduirait immanquablement à une culture planétaire uniformisée. 
C. P. : Il me paraît important de revenir sur les notions fondamentales de culture en ethnologie. La culture ne fonctionne pas seulement par emprunts, ou rejets, mais aussi par réinterprétations. Le concept de réinterprétation a été particulièrement bien étudié par Melville Herskovits, dans son analyse des différentes formes de syncrétisme en Amérique, entre les cultures africaines et les cultures d'origine européenne. La musique me parait être, comme la religion, un lieu d'influence, de brassage, d'adoption, de réinterprétation de traits d'origines diverses. On peut faire référence aux travaux de Roger Bastide (Le Prochain et le lointain, Les Amériques noires, étude des civilisations africaines dans le Nouveau Monde), qui a beaucoup étudié les phénomènes d'acculturation.

Il est nécessaire de définir clairement ce terme, à propos duquel il existe souvent un contresens : acculturé, cela ne veut pas dire sans culture ; le « a » n'est absolument pas un signe privatif. L'acculturation englobe le jeu des diverses influences qui se manifestent au sein d'une culture.

Les gens qui se sont acculturés au contact d'une société différente ont adopté des éléments de la culture de cette société. Ils n'ont pas forcément perdu la leur, même s'ils sont coupés de ses bases comme c'est le cas de certains émigrés en France. On peut même parler d'une certaine acculturation chez les provinciaux de Paris qui gardent néanmoins leurs racines régionales. Pour leurs proches, restés au pays, ils sont parisiens, et c'est vrai.

Loin d'être un phénomène d'appauvrissement, on peut analyser ces mécanismes d'emprunts comme un enrichissement, un signe du dynamisme des cultures. On peut même se demander dans quelle mesure une culture qui n'emprunte pas n'est pas une culture qui se fige et qui est appelée à disparaître. Idée que défend Lévi-Strauss, dans Race et histoire, à savoir que la force d'une culture est dans la collaboration, les emprunts - il emploie d'ailleurs les termes de «coalition, jeu en commun » et il affirme que « le progrès culturel est fonction des coalitions entre cultures $»$.

Il y a un autre contresens déclenché par le terme «acculturation », qui provient de la définition du contenu du terme «culture »dans notre société : la Culture s'entendant comme « arts et lettres »; les gens peu cultivés dans ce sens sont considérés comme sans culture. Je dis souvent, sous forme de boutade, que si le ministère de la Culture s'appelait «Arts et Lettres », le contresens n'aurait peut-être pas eu lieu.

Donc, pour résumer, les traits culturels, comme la langue, la cuisine, la religion, le vêtement, sont empruntés, adoptés, assimilés, parfois au point que l'on ne sait pas qu'ils ne font pas partie de la culture d'origine ... Certains aspects peuvent être rejetés ou expulsés, le mécanisme est d'autant plus compliqué qu'il s'agit à la fois d'un phénomène de groupe et d'un phénomène individuel, qui se juxtaposent sans fonctionner de façon similaire d'un groupe à l'autre, d'un individu à l'autre.

Ces facteurs d'intégration et de résistance sont fascinants, d'autant plus qu'ils n'ont aucun rapport avec l'intelligence et que leurs logiques posent question: qu'est-ce qui fait que deux femmes de milieux socio-culturels similaires, transplantées dans les mêmes conditions, vont se distinguer, l'une assimilant la langue de la société d'accueil, la parlant avec ses enfants, et l'autre n'en sachant pas un mot, parfois vingt ans après

Selon Bastide (in Le Prochain et le lointain), il faut distinguer deux formes 
d'acculturation, l'une formelle et l'autre matérielle.

L'acculturation formelle, c'est la transformation des formes, des manières de penser et de sentir ; elle est difficile à saisir car elle est inconsciente.

L'acculturation matérielle concerne les contenus de la conscience, l'adoption ou la réinterprétation de traits culturels tels qu'une recette de cuisine, conquise puis modifiée. On peut prendre l'exemple des enfants d'immigrés, et de la différence entre les enfants nés ici ou nés là-bas : les premiers n'introduisent pas consciemment les traits culturels français ; ils font les choses, mais ne savent pas les expliquer, c'est l'acculturation formelle. Les seconds, - ce sont les « grands » enfants, les aînés - discuteront des avantages et des inconvénients des manières de faire de la société d'accueil ; ils décideront, entre une panoplie de possibilités, d'adopter tel aspect spécifique parce qu'il leur convient : c'est l'acculturation matérielle.

E.D. : Si on adopte ces concepts pour l'étude des phénomènes musicaux, l'acculturation matérielle, ce serait par exemple l'utilisation de la guitare électrique pour les musiciens africains, parce que le son, les possibilités techniques leur conviennent; l'acculturation formelle serait l'utilisation inconsciente de certains modes ou rythmes en provenance de cultures différentes.

Mais dans ce cas une acculturation matérielle ne peut-elle pas se transformer en acculturation formelle ? Prenons l'exemple de l'accordéon, cet instrument d'origine autrichienne qui symbolise à présent la musique «bien de chez nous» (cf. l'article d'Yves Defrance « Traditions populaires et industrialisation ; le cas de l'accordéon», dans le numéro 3, tome 14, de la revue Ethnologie française).

C.P. : La citation ci-contre, extraite du Prochain et le lointain (p. 143), illustre bien ces mécanismes; elle me paraît intéressante dans le contexte de Vibrations puisqu'elle touche un domaine proche de la musique : il s'agit des transformations d'une cérémonie de danses traditionnelles religieuses.

«Le Brésil peut nous donner aussi un excellent exemple d'acculturation formelle : les Candomblés dits commerciaux ou pour touristes. Ce sont bien les mêmes gestes, le même cérémonial ou à peu près, les même pas de danses ou les mêmes leitmotivs musicaux; et par conséquent, du point de vue du « contenu », il n'existe pas de différence majeure entre eux et les candomblés traditionnels. Mais les chefs de ces candomblés ont une mentalité occidentale et non plus africaine, ayant perdu la foi. Ils voient leur religion à travers les catégories de productivité, de profit, de bénéfice; ils la gèrent en excellents commerçants, comme une entreprise rentable. Ils savent doser la part de l'érotisme (dans la danse), et la part du sadisme (dans ta transe spectaculaire), alors que le vrai candomblé ignore l'érotisme (la danse est religieuse) et le sadisme (la transe y est rarement spectaculaire) ; c'est-à-dire que ces nouveaux entrepreneurs de spectacles, ces maîtres de ballet repensent le candomblé à travers une mentalité blanche, ils le réinterprètent en termes occidentaux. La distinction entre l'acculturation matérielle et l'acculturation formelle est ici particulièrement nette puisque matériellement il n'est pour ainsi dire pas touché à la séquence des rites, comme à l'organisation des gestes, mais elles sont pensées sur un autre registre. Bien entendu, à partir de cette acculturation formelle, des changements de contenu peuvent s'introduire peu à peu, surtout là où la mémoire collective a subi le plus de pertes, comme dans la Macumba : 
ainsi le changement d'heure du sacrifice qui passe du matin au soir, de l'espace sacré également au salon de danse, ou encore de l'introduction de certains éléments de music-hall (c'est ainsi que j'ai vu l'introduction du strip-tease dans un vaudou haïtien), mais ces changements sont subsidiaires et consécutifs à une première acculturation «formelle », et ne peuvent s'expliquer qu'à partir d'elle. »

Dès lors que l'on aborde ces questions d'acculturation, il convient donc d'être excessivement vigilant et de se méfier de toute idéologie; ce qui est difficile, particulièrement lorsqu on étudie des phénomènes culturels qui nous sont proches, dans la mesure où la traditionnelle distance, spécifique à la situation ethnologique en domaine exotique, ne joue plus. Ce n'est pas parce qu'un type porte un complet veston qu'il est européen, ce n'est pas parce qu'un type est noir qu'il est de culture africaine. On peut aussi prendre l'exemple des « Beurs »: tous les enfants de type nord-africain ne sont pas «Beurs ». Beur désigne les jeunes Nord-Africains nés et élevés en France, ce qui, du point de vue de l'acculturation, renvoie au concept d'acculturation formelle mais aussi à toute cette culture des H.L.M., aux particularités de la culture de banlieue, de la «zone », qui favorise le brassage et le mélange, et qui crée un style spécifique.

Il ne faut surtout pas croire que ces mécanismes jouent à sens unique ; en gros, il s'agit d'une société receveuse dans laquelle viennent s'implanter des groupes d'origines différentes, qui ne sont pas majoritaires. On a toujours l'impression - et c'est vrai aussi, mais en partie seulement - que ceux qui arrivent empruntent des traits culturels au milieu dans lequel ils vivent désormais en abandonnant les leurs. Mais le phénomène est interactif.

Les Français sont, eux aussi, inscrits dans les mécanismes d'acculturation. Un très bon exemple peut être pris dans la cuisine. Je préfère parler de cuisine que de musique, domaine que je ne connais guère. De plus, il me semble que la musique et la cuisine se rejoignent par bien des aspects. Si l'on analyse les adoptions actuelles en France de plats d'origine étrangère, on comprend qu'il ne s'agit pas d'une sorte de «contre-acculturation». Il s'agit d'une dynamique permanente, on est tout le temps en train de s'acculturer à de nouveaux produits, surtout dans nos civilisations très urbanisées où les technologies de communication permettent la circulation rapide et multiple. Dans les grandes villes, les phénomènes de brassage sont amplifiés, les rencontres facilitées, et la diffusion, par la radio ou la télé, met en présence permanente avec des traits culturels qui nous sont étrangers. Quand on adopte un trait nouveau, c'est toujours soit parce qu'il correspond à quelque chose de profond, d'inconscient, soit parce qu'il plaît, soit encore parce qu'on peut facilement le transformer selon le modèle de sa propre culture.

Si l'on observe les restaurants grecs à Pans. Berlin ou New York, la cuisine ne change pas tellement. En revanche, les manières de table sont différentes, marquées par la culture nationale. À Paris, le couvert est mis à la française, et à New York, à l'américaine

Autre exemple, l'adoption du méchoui par les Français pose de nombreuses questions. Le méchoui est un plat d'origine nord-africaine, qui consiste à griller un mouton entier sur un feu de braises, en plein air*. Chez nous, il est adopté par

* Ou, à la mode berbère, à le cuire à l'étouffée dans un four de glaise. Cette technique n'a pas été adoptée en France, à ma connaissance, parce qu'elle est trop difficile à réaliser. 
différentes classes sociales, sauf les très pauvres car un mouton entier coûte trop cher. On le retrouve à la fois dans les classes moyennes, à l'occasion d'un baptême, d'un mariage, d'une fête du village ou du comité d'entreprise et dans les classes bourgeoises, comme summum de la fête dans la propriété de famille en Normandie. Cette adoption me semble pouvoir s'expliquer. En premier lieu, cela correspond à notre société d'abondance, où la richesse doit être montrée : il est de bon ton de se payer un mouton, et de faire une fête où l'on invite beaucoup d'amis, cela prouve que l'on est généreux et que l'on a les moyens. En second, il s'agit de la résurgence de traits archaïques, oubliés, et qui ont dû être réappris : le mode de cuisson au feu de bois était la technique de nos ancêtres. Plus que l'adoption d'un nouveau trait, on pourrait donc analyser le méchoui comme une récupération de quelque chose que nous avions perdu... Mais bien sûr, tous ces différents aspects sont tellement mêlés qu'il est difficile de parvenir à démêler clairement les choses.

Il faut encore insister sur le rôle de l'individu : deux groupes n'emprunteront pas à la culture d'accueil, ou d'importation, les mêmes choses (cuisine, vêtement, musique, etc.), et en même temps, au sein d'un groupe, deux individus ne rejetteront et n'emprunteront pas les mêmes choses. Toute modification (comme toute résistance au changement) est un message adressé à la cantonade. Et la liberté de l'individu doit y être respectée.

E. D. : La musique fournit de magnifiques exemples de confusion et de réduction, en ce qui concerne des opinions attribuant à tel groupe culturel telle capacité, je pense par exemple à la croyance que quiconque a la peau noire possède automatiquement «le sens du rythme », alors que les explications sont diverses d'un groupe à l'autre, d'un enfant noir à un autre, selon le milieu culturel et l'éducation.

Mais la musique offre des formes métissées - je préfère employer le terme mélangées - particulièrement remarquables, je pense au concert récent de Manu Dibango à Paris, devant un public mixte de blancs et de noirs. Ce musicien africain revendique son acculturation et ses diverses influences. Il joue du saxophone (qui n'est pas un instrument de musique africain traditionnel, puisque, d'origine européenne, il a été utilisé par les musiciens noirs américains pour faire du jazz), et emploie les nouvelles technologies: il y a donc chez lui une acculturation qui mélange différents horizons, différents continents.

Les concerts de musique africaine ont conservé un trait typiquement africain: sur scène, un des musiciens appelle, on pourrait presque dire sélectionne, un danseur dans le public, et celui-ci vient faire son petit numéro de danse sur scène et retourne dans le public. De tels phénomènes ne sont jamais observables dans les concerts de rock ou de jazz, où tout membre du public qui manifeste la volonté de «s'exhiber » sur scène est impitoyablement rejeté dans la salle. Un des danseurs qui est monté ce soir-là sur scène était un Antillais français (Martiniquais ou Guadeloupéen) ; « accessoirisé » aux couleurs rasta (jamaïcaines), coiffé de «dread-locks» (coiffure rasta, elle-même d'origine africaine), il dansa le «smurf », danse des adolescents des ghettos nordaméricains, spécifiquement des « Blacks » et des Portoricains.

Un autre exemple, qui ramène à l'univers plurinational des métiers artistiques, est la composition de l'orchestre de la chanteuse Myriam Makeba. D'origine sud-africaine, celle-ci vit en Guinée. Ses musiciens et choristes- 
danseuses, s'ils sont tous noirs, ont des appartenances culturelles des plus variées. Le batteur, noir américain, vit à Paris ; le bassiste, Guadeloupéen, vit à Paris, comme le pianiste, Martiniquais ; le guitariste électrique, originaire du Ghana, vit en Belgique ; deux percussionnistes : l'un, Guadeloupéen, réside à Paris, l'autre, Guinéen, réside dans son pays; un joueur de kora (harpe traditionnelle africaine) qui joue aussi de la guitare, vit en Guinée, son pays d'origine; les trois danseuses-choristes, Sud-Africaines d'origine, vivent à Londres. Entre eux, le langage commun est l'anglais, auquel se mélangent des éléments linguistiques d'origine française et guinéenne, difficilement compréhensibles pour une personne extérieure à leur groupe. On voit ici se mélanger des musiciens aux nationalités différentes, aux cultures distinctes, que leur couleur de peau et leur métier de musicien réunit. Il existe d'ailleurs une hiérarchie interne au groupe: à l'intérieur de cette unité (orchestre d'une chanteuse), les musiciens réorganisent les différences. Il serait passionnant de comprendre les normes - et les enjeux - sur lesquels repose cette hiérarchie interne.

Vic Pitts, le batteur américain, insiste sur le fait qu'il n'est pas Africain, et que souvent le public pense que tous les musiciens de cet orchestre le sont, ce qui est une grave erreur. Il ne veut pas être confondu avec un musicien traditionnel africain : pour lui, la batterie est un instrument plus complexe, qui nécessite la connaissance d'autres musiques: "Moi, je peux jouer beaucoup de styles de musique différents, je suis un vrai professionnel, alors que les percussionnistes africains, sauf quelques-uns qui connaissent bien la musique, ne peuvent jouer que la musique de leur pays ».

C. P. : Ces exemples sont intéressants. Dans le premier, la présence du public blanc prouve bien que l'acculturation n'est pas un phénomène à sens unique. Les cultures afro-américaines sont en train de pénétrer profondément la vieille Europe : juste retour des choses. La musique et la danse jonglent en souplesse avec les possibilités infinies des réinterprétations. Mais il faut noter aussi que, lorsque les territoires d'origine ont disparu, le corps reste le dernier lieu de la mémoire. Quand les grands mythes sont oubliés, les danses rituelles se perpétuent encore. Dans le second exemple, le danseur antillais qui danse le smurf lors d'un concert africain crée quelque chose d'autre, de nouveau. C'est primordial, l'idée de la culture en perpétuelle invention. La parole du batteur est importante aussi. Dans l'analyse de ces phénomènes d'acculturation, il faut nous méfier de nos yeux d'Européens quand nous cherchons à comprendre ce qu'ils signifient pour ceux qui les vivent.

Et puisque nous avons devisé de concert sur la richesse de ces mixages, je citerai pour conclure les dernières lignes des Amériques noires (Roger Bastide, Paris, 1966) :

«Les cultures afro-américaines sont loin d'être mortes, elles rayonnent au contraire et s'imposent aux Blancs. Elles pourront demain, dans un monde sans cesse changeant, donner encore de nouvelles floraisons et nourrir, de leur miel ou de leurs piments de nouvelles promesses de fruits ». 